\title{
La declaración de la víctima de violencia de género como única prueba de cargo: últimas tendencias jurisprudenciales en España
}

\author{
The declaration of the victim of the gender violence crime: \\ latest jurisprudential trends in Spain
}

\section{Alicia González Monje ${ }^{1}$}

Universidad de Salamanca - Salamanca/España alicia.g.monje@usal.es

http://orcid.org/0000-0002-9110-7406

\begin{abstract}
RESUMEN: La declaración de la víctima del delito ha ido adquiriendo cada vez mayor protagonismo en el proceso penal español, hasta el punto de convertirse en esencial para enervar la presunción de inocencia en aquellos procesos en que se constituye como única prueba de cargo. Tal circunstancia ha alcanzado mayor relevancia, aún si cabe, en los delitos relacionados con la violencia de género, caracterizados, por un lado, por las especiales particularidades que confluyen en quien además de víctima del hecho delictivo es testigo de este y, por otro, por el escaso acervo probatorio con que suele contar el juzgador en los procesos penales seguidos por tales hechos, al ser conductas estas generalmente cometidas en la intimidad de la relación de pareja. EI presente trabajo tiene por objeto analizar los parámetros orientativos proporcionados por el Tribunal Supremo español en la declaración de tales víctimas. Se examinará la posición jurisprudencial tradicional y se valorará posteriormente, de una manera crítica, la ampliación que de dichos criterios ha realizado la reciente sentencia del Tribunal Supremo 119/2009, de 6 de marzo, a fin de determinar la necesidad o no de dicha ampliación, así como la incidencia de su aplicación en los procesos seguidos por delitos relacionados con la violencia de género.
\end{abstract}

1 Profesora Ayudante de Derecho Procesal en la Universidad de Salamanca (España). Doctora en Derecho. 
Palabras-clave: declaración de la víctima; violencia de género; prueba penal.

AвSTRACT: The declaration of the victim of the crime has been gaining prominence in the Spanish criminal process, to the point of becoming essential to enervate the presumption of innocence in those processes in which it is the only proof of charge. This circumstance has become even more relevant, even if possible, in crimes related to gender violence, characterized, on the one hand, by the special characteristics that converge on someone who, in addition to being a victim of the criminal act, is a witness to it and, on the other, due to the scarce body of evidence that the judge usually has in the criminal proceedings followed by such acts, as these are behaviours generally committed in the intimacy of the couple's relationship. The purpose of this work is to analyse the guiding parameters provided by the Spanish Supreme Court in the declaration of such victims. The traditional jurisprudential position will be examined and the expansion that these criteria have made in the recent ruling of the Supreme Court 119/2009, of March 6, will be critically assessed afterward, to determine the need or not for such expansion, as well as the incidence of its application in the processes followed by crimes related to gender violence.

KEYWORDS: declaration of the victim; gender violence; criminal evidence.

ConTENIDO: Introducción; 1. La víctima como testigo cualificado o el testigo-víctima; 2 . La declaración de la víctima como única prueba de cargo; 2.1. La construcción jurisprudencial "tradicional" en España; 2.2. La nueva tendencia jurisprudencial de aplicación a la violencia de género; Conclusiones; Bibliografía.

\section{INTRODUCCIÓN}

Podemos afirmar sin rubor que la respuesta del legislador español frente a la violencia de género ha sido y es contundente. La promulgación de la Ley Orgánica 1/2004, de 28 de diciembre, de Medidas de protección integral contra la violencia de género ${ }^{2}$ es una muestra de ello, marcando

2 Ley Orgánica 1/2004, de 28 de diciembre, de Medidas de Protección Integral contra la Violencia de Género. BOE, núm. 313, de 29 de diciembre de 2004 , 
un antes y un después en la lucha contra la lacra social que representa la violencia ejercida sobre las mujeres "por parte de quienes sean o hayan sido sus cónyuges o de quienes estén o hayan estado ligados a ellas por relaciones similares de afectividad, aun sin convivencia”.

A la par se ha ido avanzando en el reconocimiento a la víctima, en general, de un papel cada vez más preponderante en el proceso penal ${ }^{4}$, culminando esta tendencia en la promulgación de la Ley 4/2015, de 27 de abril del Estatuto de la víctima del delito, con la vocación, según su Exposición de Motivos, de ser "el catálogo general de los derechos, procesales y extraprocesales, de todas las víctimas de delitos” ${ }^{5}$.

No obstante, a pesar de los avances que ello ha supuesto, en especial, en cuanto a asistencia, apoyo y reconocimiento de derechos, el silencio de las víctimas es una constante en los procesos penales seguidos por violencia de género en España. Silencio que se articula de diversas maneras, bien mediante la retirada de la denuncia inicialmente interpuesta, bien mediante el acogimiento a la llamada dispensa del deber de declarar que prevé la Ley de Enjuiciamiento Criminal en su artículo 416 para los "parientes del procesado en líneas directa ascendente y descendente, su cónyuge o persona unida por relación de hecho análoga a la matrimonial, sus hermanos consanguíneos o uterinos y los colaterales consanguíneos hasta el segundo grado civil”" tanto en fase de instrucción como en fase de juicio oral.

Según los datos proporcionados por el Observatorio contra la Violencia Doméstica y de Género del Consejo General del Poder Judicial, las renuncias de las víctimas de violencia de género al proceso oscilan

pp. 42166 a 42197.

3 Art. 1 Ley Orgánica 1/2004.

4 Señala Ortiz Pradillo que se ha pasado de "un olvido material y procesal casi absoluto" al reconocimiento de un papel principal en el proceso. ORTIZ PRADILLO, Juan Carlos. Estereotipos legales en la lucha contra la violencia machista: la irrelevancia jurídica de la voluntad de la víctima (1). Diario La Ley, n. 8697,2016, p. 2.

5 Ley 4/2015, de 27 de abril, del Estatuto de la víctima del delito. BOE, núm. 101, de 28 de abril de 2015, pp. 36569 a 36598.

6 Art. 416 LECrim. 
entre el 10,06\% en el año 2007 y el 12,4\% en los años 2014 y $2015^{7}$ en sus picos mínimo y máximo. Por su parte, las distintas Memorias de la Fiscalía General del Estado atribuyen en porcentajes elevados, entre el $33,07 \%$ y el 58,5\%, las retiradas de acusación por parte del Ministerio Público en los casos en que las víctimas se niegan a declarar en el plenario contra su agresor al hacer uso de la dispensa prevista en el artículo $416^{8}$.

Se atribuye, así, a la declaración de la víctima de violencia de género un papel preponderante en el proceso penal, no ya limitado al ejercicio tradicional de la acusación particular que le permite ser parte activa del proceso, sino haciendo depender, en muchas ocasiones, con su declaración en el juicio oral el logro de una sentencia condenatoria, según decida ejercitar o no el derecho que legalmente tiene conferido a no declarar contra el acusado pariente en aplicación del citado artículo 416 de la Ley de Enjuiciamiento Criminal ${ }^{9}$.

Esta cuestión no es baladí, si tenemos en cuenta que los delitos relacionados con la violencia de género se caracterizan precisamente por cometerse en la intimidad del domicilio, ajenos a la mirada de terceros, con una importante consecuencia y es que, en muchos casos, será la propia víctima del ilícito penal la única que pueda relatar cómo han ocurrido los hechos, encontrándose el proceso huérfano de toda prueba al margen de la declaración de la misma.

Determinar el papel que ha de tener en el proceso penal la declaración de aquella persona en la que concurren las condiciones de víctima y testigo es el objetivo principal de este trabajo, analizando la doctrina jurisprudencial consolidada en la materia, y aportando la nueva tendencia marcada por las resoluciones judiciales más recientes, a la vez que se delimita la necesidad de consolidar legalmente un estatuto procesal autónomo para la declaración del testigo-víctima que huya de valoraciones subjetivas de difícil encaje en el proceso penal.

7 CONSEJO GENERAL DEL PODER JUDICIAL. Datos estadísticos proporcionados por el Observatorio contra la Violencia Doméstica y de Género del Consejo General del Poder Judicial (2007-2018). Disponible en: www.poderjudicial.es. Acceso en: 22 de marzo de 2020.

8 FISCALÍA GENERAL DEL ESTADO. Memorias Anuales (2006-2018).

9 PIÑEIRO ZABALA, Igor. Testigo y víctima: Dispensa a declarar. Diario La Ley, n. 7519, 2010, p. 1. 


\section{LA VÍCTIMA COMO TESTIGO CUALIFICADO O EL TESTIGO-VÍCTIMA}

La confluencia en la mujer que ha sido el sujeto pasivo de un delito relacionado con la violencia de género de las condiciones de víctima y testigo coloca a la misma en un estatus procesal específico ${ }^{10}$. Es obvio que no es lo mismo ser un testigo del hecho delictivo, en el sentido de un extraño que percibe de manera directa el delito, a ser la víctima del mismo en cuanto sujeto pasivo de aquel.

Lo anterior nos lleva a concluir que la víctima en modo alguno puede ser ese "tercero ajeno a los hechos"11 como nota consustancial a la figura del testigo en sentido estricto ${ }^{12}$, lo que le confiere determinadas especificidades respecto del mismo con trascendencia en la posición que ha de atribuírsele en el proceso penal ${ }^{13}$, en especial en orden a la declaración que de los hechos sufridos pueda prestar, algo si cabe más acusado en la valoración del testimonio de un delito cometido en el ámbito de la violencia de género ${ }^{14}$.

10 Sobre la dificultad de conjugar ambas cualidades, ver: MARTÍN RÍOS, María Pilar. Víctima y justicia penal: reparación, intervención y protección de la víctima en el proceso penal. Barcelona: Editorial Atelier, 2012, p. 134.

11 MAGRO SERVET, Vicente. La imposibilidad de conceder a las víctimas de la violencia de género la dispensa de declarar contra sus agresores (art. 416 LECrim): ¿es necesaria una reforma legal?. Diario La Ley, n. 6333, 2005, p. 12.

12 Tal consideración sería necesaria en materia de protección. MARTÍN RÍOS, María Pilar. Reflexiones acerca de la negativa a declarar en juicio de la mujer víctima de violencia de género: análisis de la jurisprudencia española. Revista General de Derecho Procesal, n. 15, 2008, p. 3.

13 En contra de la consideración de la víctima como testigo cualificado: RAMÍREZ ORTIZ, José Luis. Perspectiva de género, prueba y proceso penal: Una reflexión crítica. Valencia: Tirant lo Blanch, 2019, pp. 147-149.

14 No le falta razón a Balerdi Múgica cuando señala que "analizar y valorar testimonios propios del enjuiciamiento de delitos relacionados con la violencia de género, atendiendo exclusivamente parámetros de racionalidad, diseñados y previstos para su aplicación a supuestos de total desvinculación víctima/ agresor, constituya camino propicio hacia una desenfocada comprensión del conflicto". BALERDI MÚGICA, José Manuel. El testimonio en delitos de violencia de género en la jurisprudencia. Valoración y efectos probatorios. En: ÉRICE MARTÍNEZ, María Esther (Dir.). Práctica y valoración de la prueba en violencia de género. Madrid: Cuadernos Digitales de Formación, Consejo General del Poder Judicial, 2009, p. 54. 
A pesar de lo expuesto, y aunque la distinta posición que ocupan el testigo en sentido estricto y el testigo-víctima se reconocen sin ambages por la doctrina ${ }^{15}$ y la jurisprudencia española, aún no se ha abordado de manera integral en el ordenamiento jurídico español el tratamiento que ha de tener la declaración de la víctima en el proceso penal, laguna que tradicionalmente ha sido colmada con construcciones jurisprudenciales, sin que exista plasmación legislativa al respecto.

Recientemente y con carácter general, el Tribunal Supremo español, en Sentencia 282/2018, de 13 de junio, aboga por una reforma procesal en la que se plasme la distinta posición que tiene en el proceso quien ostenta la condición de víctima en comparación con quien es testigo en sentido estricto, y que esa diversa posición tenga reflejo en lo que a los medios de prueba se refiere, argumentando que lo contrario, esto es, considerar a la víctima un mero testigo, "desnaturaliza la verdadera posición en el proceso penal de la víctima"16.

En la misma línea ya se habían pronunciado Castillejo Manzanares y Serrano Massip, al considerar necesario establecer un estatuto jurídico de la víctima en el proceso penal, con distinciones respecto al testigo en sentido estricto en cuanto al deber y dispensa de declarar, entre otras cuestiones ${ }^{17}$. Da un paso más allá, en el ámbito que nos ocupa, Fuentes Soriano, al reclamar un sistema probatorio que se adapte a las particularidades de los delitos relacionados con la violencia de género ${ }^{18}$.

En todo caso, aunque la atribución de este estatuto privilegiado autónomo ${ }^{19}$ de la declaración de la víctima, independiente al consagrado

15 MORENO CATENA, Víctor; CORTÉS DOMÍNGUEZ, Valentín. Derecho Procesal Penal. Valencia: Tirant lo Blanch, 2019, pp. 455-456. STS 282/2018, de 13 de junio. ROJ: STS 2182/2018 - ECLI:ES:TS:2018:2182.

17 CASTILLEJO MANZANARES, Raquel; SERRANO MASSIP, Mercedes. Denuncia y dispensa del deber de declarar. En: CASTILLEJO MANZANARES, Raquel (Dir.). Violencia de género y justicia. Santiago de Compostela: Universidade de Santiago de Compostela, 2013, p. 579.

18 FUENTES SORIANO, Olga. Los procesos por violencia de género. Problemas probatorios tradicionales y derivados del uso de las nuevas tecnologías. Revista General de Derecho Procesal, n. 44, 2018, p. 3.

19 Tal como ya proponía Magro Servet. Ver: MAGRO SERVET, Vicente. Hacia una ley integral de la víctima en el proceso penal: una propuesta sistemática. Diario La Ley, n. 7226, 2009, p. 4. 
para la prueba testifical en sentido estricto, no se ha producido ${ }^{20}$, no es menos cierto que el legislador español ha dado algún tímido paso hacia la diferenciación de ambas posiciones, pues, consciente de las particulares circunstancias que concurren en quienes confluyen la condición de víctima y testigo, prevé una modificación del artículo 433 LECrim $^{21}$, en virtud del apartado once de la Disposición Final primera de la Ley 4/2015, de 27 de abril, del Estatuto de la víctima del delito, para reconocer así que aquella pueda hacerse acompañar por otra persona elegida por ella misma en la práctica de la declaración testifical.

De la referida reforma podemos extraer dos consecuencias: en primer lugar, que se introducen por primera vez en la regulación de la prueba testifical dos conceptos diferenciados: el de testigo en sentido

20 Apreciando la dificultad de tal cometido "en función de la propia configuración del objeto del proceso penal a partir del elemento subjetivo", ver: SERRANO MASSIP, Mercedes. La víctima de la violencia de género ante el deber de denunciar y declarar en el proceso penal. Revista General de Derecho Procesal, n. 29, 2013, p. 16.

21 Art. 433 LECrim: "Al presentarse a declarar, los testigos entregarán al secretario la copia de la cédula de citación.

Los testigos mayores de edad penal prestarán juramento o promesa de decir todo lo que supieren respecto a lo que les fuere preguntado, estando el Juez obligado a informarles, en un lenguaje claro y comprensible, de la obligación que tienen de ser veraces y de la posibilidad de incurrir en un delito de falso testimonio en causa criminal.

Los testigos que, de acuerdo con lo dispuesto en el Estatuto de la Víctima del Delito, tengan la condición de víctimas del delito, podrán hacerse acompañar por su representante legal y por una persona de su elección durante la práctica de estas diligencias, salvo que en este último caso, motivadamente, se resuelva lo contrario por el Juez de Instrucción para garantizar el correcto desarrollo de la misma.

En el caso de los testigos menores de edad o personas con la capacidad judicialmente modificada, el Juez de Instrucción podrá acordar, cuando a la vista de la falta de madurez de la víctima resulte necesario para evitar causarles graves perjuicios, que se les tome declaración mediante la intervención de expertos y con intervención del Ministerio Fiscal. Con esta finalidad, podrá acordarse también que las preguntas se trasladen a la víctima directamente por los expertos o, incluso, excluir o limitar la presencia de las partes en el lugar de la exploración de la víctima. En estos casos, el Juez dispondrá lo necesario para facilitar a las partes la posibilidad de trasladar preguntas o de pedir aclaraciones a la víctima, siempre que ello resulte posible.

El Juez ordenará la grabación de la declaración por medios audiovisuales". 
estricto, y el de testigo-víctima ${ }^{22}$, que ha de serlo conforme a los dispuesto en el Estatuto de la víctima del delito, comprendiendo tanto a la víctima directa $^{23}$ como indirecta $^{24} ; \mathrm{y}$, en segundo lugar, que el alcance de la diferenciación es limitado, en el sentido de no ir más allá de otorgar a la víctima-testigo un plus de consideración, un derecho extraprocesal para que pueda estar acompañada mientras presta declaración, lo cual obedece, a nuestro juicio, a la propia finalidad del Estatuto, que no es otra, según su Exposición de Motivos, que la "salvaguarda integral de la víctima", en un "concepto amplio de reconocimiento, protección y apoyo" 25 de la misma, pero sin que tenga mayor reflejo en el plano de sus derechos procesales.

\section{LA DECLARACIÓN DE LA VÍCTIMA COMO ÚNICA PRUEBA DE CARGO}

La víctima es una de las dos partes de un hecho delictivo, es el sujeto pasivo del mismo y, como ya se ha señalado reiteradamente, no

${ }^{22}$ Nótese que no hace diferencia alguna por el tipo de delito.

23 Víctima directa será, según el art. 2 a) del la Ley 4/2015, "toda persona física que haya sufrido un daño o perjuicio sobre su propia persona o patrimonio, en especial lesiones físicas o psíquicas, daños emocionales o perjuicios económicos directamente causados por la comisión de un delito".

24 Víctima indirecta será, según el art. 2 b) del la Ley 4/2015, "en los casos de muerte o desaparición de una persona que haya sido causada directamente por un delito, salvo que se tratare de los responsables de los hechos: $1 .^{\circ} \mathrm{A}$ su cónyuge no separado legalmente o de hecho y a los hijos de la víctima o del cónyuge no separado legalmente o de hecho que en el momento de la muerte o desaparición de la víctima convivieran con ellos; a la persona que hasta el momento de la muerte o desaparición hubiera estado unida a ella por una análoga relación de afectividad y a los hijos de ésta que en el momento de la muerte o desaparición de la víctima convivieran con ella; a sus progenitores y parientes en línea recta o colateral dentro del tercer grado que se encontraren bajo su guarda y a las personas sujetas a su tutela o curatela o que se encontraren bajo su acogimiento familiar. $2 .^{\circ}$ En caso de no existir los anteriores, a los demás parientes en línea recta y a sus hermanos, con preferencia, entre ellos, del que ostentara la representación legal de la víctima".

25 Exposición de Motivos de la Ley 4/2015, de 27 de abril del Estatuto de la víctima del delito. 
puede considerarse un tercero ajeno a los hechos. Tal consideración hizo que la jurisprudencia española se cuestionara el papel que habría que reconocerle a la declaración de aquella en el proceso penal, llegando a la conclusión de que puede constituirse en prueba de cargo única para enervar la presunción de inocencia, siempre que se practique con las debidas garantías y se haya introducido en el proceso de acuerdo con los principios de publicidad, contradicción e inmediación, en coherencia, por un lado, con el sistema de libre valoración de la prueba que rige en el proceso penal español, y de otro, para colmar la laguna de impunidad que se produciría en la comisión de aquellos delitos que se producen fundamentalmente en la intimidad, entendida ésta como un escenario propicio fuera del alcance de los ojos de terceros ${ }^{26}$.

El papel asignado a la víctima por medio de su declaración adquiere, por tanto, un especial protagonismo en los procesos seguidos por violencia de género, en la medida en que los hechos delictivos que los motivan se producen con frecuencia en la intimidad del domicilio ${ }^{27}$, con la sola presencia de víctima y victimario ${ }^{28}$, circunstancia que por sí misma dificulta el proceso probatorio. Por ello, es frecuente que en un elevado número de estos procesos se cuente sólo con la declaración de la víctima como única prueba de cargo $^{29}$, encontrándonos sin testigos

26 STS 238/2011, de 21 de marzo. ROJ: STS 1991/2011 - ECLI:ES:TS:2011:1991.

27 MIRANDA ESTAMPRES, Manuel. Particularidades de la prueba en los delitos de violencia de género. En: DE HOYOS SANCHO, Montserrat (Dir.). Tutela jurisdiccional frente a la violencia de género. Aspectos procesales, civiles, penales y laborales. Valladolid: Editorial Lex Nova, 2009, pp. 453-454.

28 Entendiéndose que "nadie ha de sufrir el perjuicio de que el suceso que motiva el procedimiento penal se desarrolle en la intimidad víctima e inculpado, so pena de propiciar situaciones de incuestionable impunidad", pudiendo, en consecuencia, condenarse con la declaración de un solo testigo, incluso cuando su testimonio se enfrenta a varios que se expresan en dirección opuesta, como señala la STS 725/2007, de 13 de septiembre (con cita de las STSS 409/2004, de 24 de marzo, 104/2002, de 29 de enero, y 2035/2002, de 4 de diciembre). ROJ: STS 6124/2007 - ECLI:ES:TS:2007:6124.

29 En un estudio del Consejo General del Poder Judicial español del año 2009, de las 606 sentencia totales analizadas, en 34 de ellas la declaración de la víctima constituyó prueba de cargo única, dando lugar a 14 sentencias condenatorias, y 11 absolutorias, más 9 casos en que se valoraron otros aspectos. CONSEJO GENERAL DEL PODER JUDICIAL, GRUPO DE EXPERTOS Y EXPERTAS EN VIOLENCIA DOMÉSTICA Y DE GÉNERO DEL CGPJ. Estudio 
que hayan presenciado los hechos y sin vestigios materiales del delito, como en el caso de las amenazas o coacciones; en definitiva, sin dato objetivo alguno que sirva de corroboración a la declaración de los sujetos activo y pasivo del delito, los cuales ostentarán, como es lógico, posiciones contrapuestas.

En este orden de cosas, de la doctrina jurisprudencial consolidada en la materia, podemos extraer una serie de afirmaciones pacíficamente admitidas, entre otras, que la declaración de la víctima es prueba directa y no prueba indiciaria; que no se convierte de manera automática en prueba de cargo, pues en todo caso está sometida a la valoración del tribunal; que dichas declaraciones no son totalmente asimilables a las de un tercero; que "tienen valor de prueba testifical, siempre que se practiquen con las debidas garantías y son hábiles por sí solas para desvirtuar la presunción constitucional de inocencia"; y que "cuando es la única prueba de cargo exige una cuidada valoración” por el juez o tribunal ${ }^{30}$.

En aquellos procesos penales en los que, por tanto, la declaración de la víctima integre de manera única el acervo probatorio, debemos plantearnos cómo encontramos el equilibrio necesario entre el derecho a la presunción de inocencia del presunto autor del delito y la legítima expectativa de justicia que se le ha de presuponer a toda víctima ${ }^{31}$. Más en concreto, qué parámetros han de concurrir en esa declaración para que tenga el valor de prueba testifical incriminatoria, de cargo, de manera que la misma no dependa únicamente de la impresión subjetiva del juzgador obtenida por la necesaria inmediación de su práctica, sino que pueda apoyarse en componentes de carácter objetivo que

sobre la Aplicación de la Ley Integral contra la violencia de género por las Audiencias Provinciales, p. 38. Disponible en: www.poderjudicial.es. Acceso en: 22 de marzo de 2020.

30 Por todas, en esta materia, la STS 119/2019, de 6 de marzo. ROJ: STS 678/ 2019 - ECLI:ES:TS:2019:678.

31 Para un estudio profundo de la tensión entre ambas cuestiones en los delitos relacionados con la violencia de género, ver: MARTÍN DIZ, Fernando. Presunción de inocencia en procesos penales por violencia de género. Revista Ius et Praxis, n. 3, 2018, pp. 19-66. 
le permitan formar con acierto su convicción ${ }^{32}$, y todo sin que ello suponga una merma en las garantías procesales del acusado ${ }^{33}$.

La trascendencia es tal, que se ha afirmado que cuando la declaración de la víctima constituye la única prueba de cargo, se produce una "situación límite de riesgo" ${ }^{44}$ para el derecho a la presunción de inocencia ${ }^{35}$, extremándose ese riesgo si es la víctima "quien inició el proceso mediante la correspondiente denuncia o querella, haciéndose aún más acentuado si ejerce la acusación, pues en tal caso se constituye en única prueba de la acusación al propio acusador"36.

32 Teniendo en cuenta, como señala Balerdi Múgica, que "Se trata de requisitos que no garantizan la veracidad de la declaración, pero que orientan para disminuir las posibilidades de error en la valoración”. BALERDI MÚGICA, José Manuel. El testimonio en delitos de violencia de género en la jurisprudencia. Valoración y efectos probatorios”. En: ÉRICE MARTÍNEZ, María Esther (Dir.). Práctica y valoración de la prueba en violencia de género. Madrid: Cuadernos Digitales de Formación, Consejo General del Poder Judicial, 2009, p. 59.

33 En este sentido, debemos tener en cuenta lo declarado en la STS 278/2007, de 10 de abril, cuando establece que "hay que afirmar que no existe un estándar de prueba menos exigente para los casos de acciones cometidas en la clandestinidad; aunque tal sea lo que podría entenderse a partir de algunas afirmaciones poco afortunadas de cierta jurisprudencia. El derecho a la presunción de inocencia es de carácter absoluto: cualquiera que sea la imputación, debe estar bien acreditada en todos sus elementos centrales, para que pueda dar lugar a una sentencia condenatoria. Y el supuesto argumento -de frecuente invocación- de la necesidad de evitar la impunidad de acciones producidas sin la concurrencia de testigos, privilegiando para ello, alguna clase de prueba, no se sostiene. Pues el sistema punitivo conoce una sola forma de dar respuesta constitucionalmente válida a los actos penalmente relevantes, es la fundada en el respeto de la presunción de inocencia como regla de juicio. Y ésta exige que cualquier condena tenga como soporte una convicción de culpabilidad más allá de toda duda razonable, racionalmente formada, y argumentada de manera convincente a partir de datos probatorios bien adquiridos”. ROJ: STS 2277/2007 - ECLI:ES:TS:2007:2277.

34 Por todas, la STS 1346/2002, de 18 de julio. ROJ: STS 5470/2002 - ECLI: ES:TS:2002:5470.

35 Sobre los riesgos para el derecho a la presunción de inocencia: CABEZUDO RODRÍGUEZ, Nicolás. Del principio de inmediación, sus excepciones y los instrumentos tecnológicos. Valencia: Tirant lo Blanch, 2010, pp. 97-99.

36 En esta línea, la STS 7/2016, de 20 de enero. ROJ: STS 81/2016 - ECLI: ES:TS:2016:81. 
Ahora bien, para atribuirle tal valor probatorio, y poder excluir que concurran otras razones que incidan en la veracidad de lo declarado, se requiere que la valoración que realiza el juzgador se ajuste a una serie de parámetros que habrán de ser ponderados por el mismo.

La fijación de tales criterios se ha realizado por el Tribunal Supremo español en una dilatada producción jurisprudencial, con la intención de proporcionar al juzgador de instancia una serie de parámetros que le ayuden a formar su convicción ${ }^{37}$, sin desconocer la importancia de la inmediación en cuanto "contacto directo con la fuente de prueba" 38 .

Así, y respecto de los mencionados criterios o parámetros, se hace necesario realizar una serie de consideraciones previas al examen de los mismos, extraídas de la propia doctrina jurisprudencial, que nos van a permitir situar el alcance que tradicionalmente se les viene atribuyendo:

a) En primer lugar, que no estamos ante requisitos de validez como los que operarían en un sistema de prueba legal o tasada ${ }^{39}$, sino ante "estándares orientados a facilitar la objetivación y la expresión de la valoración del cuadro probatorio" ${ }^{40}$, no siendo, por tanto, verdades incontrovertibles ${ }^{41}$.

b) En segundo lugar, que tales criterios orientativos no han de concurrir cumulativamente ${ }^{42}$.

c) Y en tercer lugar, que tienen un valor relativo ${ }^{43}$, en un triple sentido: en la medida en que la insuficiencia en uno de los criterios

37 Teniendo en cuenta que según la STS 57/2019, de 5 de febrero, "no quiere decir que sean reglas de valoración de la prueba que sustituyan la libre evaluación que corresponde a los tribunales de instancia, convirtiendo así a la prueba testifical en una suerte de prueba tasada legalmente en cuanto a las condiciones de su eficacia demostrativa”. ROJ: STS 328/2019 - ECLI:ES:TS:2019:328. STS 570/2009, de 21 de mayo. ROJ: STS 3567/2009 - ECLI:ES:TS:2009:3567. STS 150/2015, de 18 de marzo. ROJ: STS 1390/2015 - ECLI:ES:TS:2015:1390. En tal sentido, la STS 437/2015, de 9 de julio. ROJ: STS 3491/2015 - ECLI: ES:TS:2015:3491.

41 VELASCO NÚÑEZ, Eloy. "Conclusiones del Seminario La prueba en el proceso penal”. Madrid: Conclusiones de Seminarios, Consejo General del Poder Judicial, 2008, p. 7.

42 Así se dispone en la STS 381/2014, de 21 de mayo. ROJ: STS 2027/2014 ECLI:ES:TS:2014:2027.

43 SegúnlaSTS3/2015, de 20 de enero.ROJ:STS 178/2015-ECLI:ES:TS:2015:178 
puede compensarse con la fuerza de los demás; en el sentido de que "un insuficiente cumplimiento de los tres módulos de contraste impide que la declaración inculpatoria pueda ser apta por sí misma para desvirtuar la presunción de inocencia" ${ }^{44}$; y en el entendimiento de que la concurrencia de los tres criterios no supone automáticamente la enervación de la presunción de inocencia, sino que dependerá de la libre valoración del tribunal con una adecuada motivación ${ }^{45}$.

\subsection{LA CONSTRUCCIÓN JURISPRUDENCIAL "TRADICIONAL" EN ESPAÑA}

Pasemos a analizar los criterios en cuestión, siguiendo lo dispuesto en la reciente Sentencia del Tribunal Supremo 717/2018, de 17 de enero de $2019^{46}$, por entender que aúna toda la doctrina jurisprudencial en la materia:

\section{A) Ausencia de incredibilidad subjetiva}

La falta de credibilidad subjetiva se ha asociado tradicionalmente por la jurisprudencia, en primer lugar, a la concurrencia de determinadas circunstancias de carácter físico o psíquico que pudieran concurrir en un testigo, haciendo más débil su testimonio, como pueden ser la ceguera, la sordera o incluso la edad; a lo que habría que añadir la incidencia que algunas dependencias como al alcohol o a las drogas pudieren tener sobre la credibilidad del testimonio ${ }^{47}$.

44 STS 355/2015, de 28 de mayo. ROJ: STS 2599/2015 - ECLI:ES:TS:2015:2599.

45 Como señala la STS 150/2015, de 18 de marzo, "no es que el contenido de una testifical que supere ese triple filtro deba ser tenido como válidamente inculpatorio. Lo único que cabe sostener es que un testimonio que no lo hiciera debería ser desestimado ad limine como medio de prueba; mientras que, en el caso contrario, resultará atendible en principio, y, por tanto, estará justificado pasar -en un segundo momento- a confrontar sus aportaciones con las de otra procedencia, para tratar de confirmar la calidad de los datos". ROJ: STS 1390/2015 - ECLI:ES:TS:2015:1390. STS717/2018,de17deenerode2019.ROJ:STS111/2019-ECLI:ES:TS:2019:111. delitos de violencia de género. En: CUETO MORENO, Cristina; GÓMEZ VILLORIA, José María (Dirs.). Criterios de actuación judicial frente a la violencia 
En segundo lugar, atacará la credibilidad del testimonio la concurrencia de móviles espurios, en función de las relaciones entre las partes, debiendo descartarse que "la declaración inculpatoria se ha podido prestar por móviles de resentimiento, venganza o enemistad u otra intención espuria que pueda enturbiar su credibilidad" ${ }^{48}$.

Por otro lado, la praxis judicial nos ha aportado otras circunstancias que han cuestionado el requisito de ausencia de incredibilidad subjetiva, como es el caso del retraso en denunciar los hechos, especialmente en el ámbito de la violencia de género. No obstante, se ha entendido que estamos ante delitos en los que concurren características especiales, derivadas principalmente de la afectividad compartida entre víctima y victimario ${ }^{49}$, que hace que este tipo concreto de víctima reaccione de manera distinta a como lo haría la víctima de cualquier otro delito ${ }^{50}$.

Por otro lado, con frecuencia se ha puesto en duda la credibilidad de la víctima por el sólo hecho de tener abierto un proceso civil de separación o divorcio, algo que resulta inadmisible, máxime si tenemos en cuenta que, es precisamente en tales supuestos cuando se produce un incremento del riesgo de que la mujer sufra algún tipo de agresión, que suele ser, por otro lado, de extrema gravedad ${ }^{51}$. Y lo mismo se ha señalado en los supuestos en que la víctima ha renunciado a las acciones civiles que le pudieran corresponder por los hechos denunciados ${ }^{52}$.

B) Verosimilitud del testimonio

El parámetro de la verosimilitud del testimonio o credibilidad objetiva tiene una doble vertiente: por un lado, la que hace referencia

de género. Madrid: Cuadernos Digitales de Formación, Consejo General del Poder Judicial, 2014, p. 103. EN VIOLENCIA DOMÉSTICA Y DE GÉNERO DEL CGPJ. Guía de criterios de actuación judicial frente a la violencia de género. Disponible en: www. poderjudicial.es. Acceso en: 25 de marzo de 2020, p. 120.

52 La STS 404/2005, de 25 de marzo, señala, en este punto, que no puede sostenerse "que las víctimas que solicitan indemnizaciones puedan tener menor credibilidad que quienes renuncian a ellas”. ROJ: STS 1853/2005 - ECLI:ES:TS:2005:1853. 
a la lógica de la declaración o coherencia interna ${ }^{53}$; y por otro, la que se sustenta sobre la existencia de corroboraciones objetivas y periféricas de dicha declaración o coherencia externa, como pueden ser lesiones objetivables a través de los correspondientes partes médicos o algún testigo que pudo apreciar el estado de la víctima en momentos inmediatamente posteriores a la producción del hecho delictivo ${ }^{54}$.

No obstante, no podemos olvidar, como acertadamente manifiesta nuestro Tribunal Supremo, que "corroborar implica vivificar, dar mayor fuerza a una verdadera prueba de cargo" ${ }^{55}$, de manera que hay que tener en cuenta que esos elementos corroboradores sólo tienen sentido como dato de refuerzo de lo declarado por la víctima, no pudiendo suplir la fuerza probatoria que tal declaración tiene.

Tal como se ha señalado, las singulares circunstancias en las que se perpetran los delitos relacionados con la violencia de género, circunscritos a la intimidad de la pareja y ajenos a la mirada de terceros, hacen especialmente dificultoso que se pueda recurrir a elementos corroboradores externos y periféricos de ese relato fáctico de la víctima, hasta el punto de que se ha sostenido por Fuentes Soriano que la exigencia de datos periféricos objetivos impide reconocer viabilidad a la declaración de la víctima como única prueba de cargo, en la medida en que será necesaria la prueba de determinados indicios ${ }^{56}$.

Por otro lado, en esta vertiente de la llamada credibilidad objetiva es frecuente el recurso, por parte de las defensas, a pruebas periciales psicológicas para determinar el grado de credibilidad del testimonio de la víctima, lo que ha dado lugar a diferentes estudios que proponen la necesidad de la evaluación psicológica-forense de la credibilidad de la víctima ${ }^{57}$.

53 Lo que, según la STS 238/2011, de 21 de marzo, “exige valorar si su versión es o no insólita, u objetivamente inverosímil por su propio contenido". ROJ: STS 1991/2011 - ECLI:ES:TS:2011:1991. STS605/2019, de10dediciembre.ROJ:STS3926/2019-ECLI:ES:TS:2019:3926. STS 24/2015, de 21 de enero. ROJ: STS 216/2015 - ECLI:ES:TS:2015:216. FUENTES SORIANO, Olga. El enjuiciamiento de la violencia de género. Madrid: Editorial Iustel, 2009, pp. 124-125.

57 Ver: ARCE FERNÁNDEZ, Ramón; FARIÑA RIVERA, Francisca. La posible simulación de la víctima. Evaluación psicológico-forense de la credibilidad y el 
Otros operadores jurídicos, no obstante, han alertado sobre el uso de esta diligencia de prueba, sosteniendo que "las periciales psicológicas a los agresores van encaminadas a la búsqueda de algún tipo de circunstancia modificativa de su responsabilidad criminal (eximentes y atenuantes), mientras que las periciales psicológicas a las víctimas, o no se practican, o van encaminadas a valorar su credibilidad y no a su verdadera finalidad, que es determinar la sintomatología derivada de violencia física y psíquica habitual y el daño moral o psicológico que aquella haya podido padecer"58.

La posición de nuestra jurisprudencia es clara al respecto, resumiendo la misma Magro Servet, en dos conclusiones:

“a) Que la pericial psicológica sobre la credibilidad del testimonio nunca puede sustituir a la valoración que corresponde al tribunal de instancia que directamente ha percibido la prueba.

b) Se trata de herramientas que pueden ser utilizadas por el tribunal para conformar una convicción y dotarla de racionalidad en la expresión de la convicción, como el tribunal ha realizado, pero sin llegar a sustituirle en esa función" ${ }^{59}$.

Por último, hay que tener en cuenta que, en otras ocasiones, la credibilidad de la víctima pretende ser socavada con prueba pericial psiquiátrica o psicológica sobre la misma, algo que sólo debe admitirse con carácter excepcional ${ }^{60}$.

daño psíquico mediante el sistema de evaluación global. En: RIVAS VALLEJO, María Pilar; BARRIOS BAUDOR, Guillermo Leandro (Dirs.). Violencia de Género. Perspectiva Multidisciplinar y Práctica Forense. Cizur Menor: Thomson Reuters Aranzadi, 2014, pp. 357-367.

ASOCIACIÓN DE MUJERES JURISTAS THEMIS. Evaluación del tratamiento judicial de la violencia de género en el ámbito de la pareja, p. 4. Disponible en: https://www.mujeresjuristasthemis.org/funcion-themis/biblioteca/category/15-penal. Acceso en: 25 de marzo de 2020.

MAGRO SERVET, Vicente. La valoración de la declaración de la víctima en el proceso penal (especial referencia a la viabilidad de la prueba pericial acerca de la veracidad de su testimonio). Diario La Ley, n. 7013, 2008, p. 12.

La jurisprudencia llama a ser especialmente rigurosos en estos casos, ya que, según la STS 381/2014, de 21 de mayo, ROJ: STS 2027/2014 - ECLI:ES:TS:2014:2027, "quien comparece como testigo en el juicio oral cumpliendo el mandato del art. $118 \mathrm{CE}$, no puede hacerlo bajo un régimen de inseguridad y de incertidumbre que acabe siendo examinado sobre aspectos íntimos de su persona y vida. Por ello puede afirmarse su principio general de prohibición de prueba cuando 
En definitiva, entendemos que la existencia de un historial de maltrato previo no puede llevar a entender per se que la víctima falta a la verdad en su declaración, de manera que se genere una duda sobre la credibilidad de su testimonio ${ }^{61}$. Y es precisamente cuando concurre alguna circunstancia de resentimiento cuando adquiere especial relevancia la realización de una motivación suficientemente detallada, mediante un filtro cuidadoso de la declaración en cuestión, que permitirá al juzgador no descartarla cuando la misma, pese a las características señaladas, tenga solidez, firmeza y veracidad objetiva ${ }^{62}$.

\section{C) Persistencia en la incriminación}

El tercer parámetro a tener en cuenta a la hora de valorar la declaración de la víctima es la persistencia en la incriminación, cuyo contenido, perfilado jurisprudencialmente, se centra en los siguientes puntos:

a) Se exige, en primer lugar, que exista una cierta uniformidad en las sucesivas declaraciones que presta la víctima en las distintas fases del proceso, de manera que no puedan apreciarse en las mismas modificaciones sustanciales, entendiéndose que no se trata de la "repetición de un disco o lección aprendida, sino en la constancia sustancial de las diversas declaraciones" ${ }^{63}$.

b) En segundo lugar, la declaración de la víctima ha de ser detallada $\mathrm{y}$, por tanto, huyendo de generalidades.

c) En tercer lugar, las diferentes declaraciones prestadas por la víctima a lo largo de todo el iter procesal no han de contradecirse entre ellas, algo especialmente difícil en las declaraciones prestadas por víctimas de violencia de género ${ }^{64}$.

recaiga sobre datos protegidos por el derecho a la intimidad del testigo y cuya finalidad no sea la de acreditar hechos del proceso sino simplemente la aportación de máximas de experiencia técnica sobre la credibilidad del testimonio".

61 De manera muy gráfica lo expone la STS 184/2019, de 2 de abril. ROJ: STS 1071/2019 - ECLI:ES:TS:2019:1071.

62 Así se desprende de la STS 717/2018, de 17 de enero de 2019. ROJ: STS 111/2019 - ECLI:ES:TS:2019:111 STS 849/1998, de 18 de junio. ROJ: STS 4053/1998 - ECLI:ES:TS:1998:4053. 
La dificultad en la concurrencia del parámetro de la persistencia en la incriminación, ha motivado que el propio Tribunal Supremo matice su valoración, entendiendo que no se considerará una quiebra del mismo "el cambio del orden en las afirmaciones; las sucesivas ampliaciones cuando no se afecta la coherencia y significación sustancial de lo narrado; la modificación del vocabulario ni de las formas expresivas cuando con unas u otras se sigue diciendo lo mismo; los cambios en lo anecdótico o en lo secundario, cuando solo implican falta de certeza en lo accesorio, pero no en lo principal, que es lo que por su impacto psicológico permanece en la mente de la víctima, salvo en los casos en que los cambios narrativos de lo secundario evidencian tendencia a la fabulación imaginativa, valorable en el ámbito de la credibilidad subjetiva" ${ }^{5}$.

En definitiva, la contradicción debe ser "nuclear y esencial", esto es, relevante ${ }^{66}$, en el sentido de aquello que es antagónico u opuesto a otra $\cos ^{67}$.

En atención a todo lo anteriormente expuesto, se puede afirmar que no hay impedimento legal alguno para que la declaración de la víctima como prueba, en ocasiones única, de cargo pueda fundamentar la destrucción de la presunción de inocencia, una vez apreciadas por el tribunal, según su conciencia, las pruebas practicadas en juicio conforme a las reglas de la sana crítica ${ }^{68}$. No obstante, cuando así fuere, esto es, al realizar el correspondiente juicio de credibilidad, el juzgador habrá de redoblar su "esfuerzo de motivación fáctica cuyas exigencias se acrecientan"

Al deber de motivación, especialmente en las sentencias dictadas en los procesos por violencia de género, se refiere también la "Guía de criterios de actuación judicial frente a la violencia de género” del Consejo

65 Según STS 238/2011, de 21 de marzo. ROJ: STS 1991/2011 - ECLI:ES: TS:2011:1991.

66 En este sentido, FUENTES SORIANO, Olga. Investigación y prueba de los delitos de violencia contra la mujer. En: GONZÁLEZ-CUELLAR SERRANO, Nicolás (Dir.). Investigación y prueba en el proceso penal. Madrid: Colex, 2006, p. 253; LUACES GUTIÉRREZ, Ana Isabel. La exención del deber de declarar de las víctimas de violencia de género. Práctica de Tribunales, n. 101, 2013, p. 46. STS 349/2019, de 4 de julio. ROJ: STS 2228/2019 - ECLI:ES:TS:2019:2228.

68 Art. 741 LECrim.

69 STS 99/2018, de 28 de febrero. ROJ: STS 619/2018 - ECLI:ES:TS:2018:619. 
General del Poder Judicial, para exigir que, en estos casos, la motivación de las sentencias comprenda el análisis de la declaración de la víctima como prueba de cargo, "explicitando las razones por las cuales el/la juez/a otorga mayor crédito a la versión de una de las partes frente a la otra". Añadiendo que en los supuestos en que la víctima se acoge a la dispensa del deber de declarar, "la motivación debería comprender expresamente la relevancia que otorga, absuelva o condene, al resto de pruebas, en particular la de todas aquellas que pudieran constituir prueba indiciaria"70.

\subsection{LA NUEVA TENDENCIA JURISPRUDENCIAL DE APLICACIÓN A LA VIOLENCIA DE GÉNERO}

A falta de regulación legal específica en el ordenamiento jurídico español sobre el valor que ha de darse a la declaración de la víctima como prueba de cargo, el Tribunal Supremo ha matizado recientemente su doctrina consolidada en la materia en referencia específica, inicialmente, a la víctima de delitos relacionados con la violencia de género.

Esta tendencia jurisprudencial se enmarca en conferir a la declaración de la víctima de violencia de género una posición privilegiada que tiene repercusión en la valoración que realizará el juez o tribunal sobre la misma. Ya en la Sentencia de 13 de junio de 2018, nuestro Tribunal Supremo viene a señalar que la fundamentación de este carácter privilegiado viene asociada al hecho de que la víctima ha vivido el delito en primera persona, lo que hace recomendable que el Tribunal preste atención, no sólo a lo narrado por aquella, sino también a la forma en que lo hace, valorando incluso "sus gestos, sus respuestas y su firmeza ante el interrogatorio al que será sometida en el juicio oral"11.

Esta tendencia se consolida con la reciente Sentencia del Tribunal Supremo 119/2019, de 6 de marzo, merecedora de cierta reflexión para poder situar el punto exacto en el que nos encontramos en esta materia.

70 CONSEJO GENERAL DEL PODER JUDICIAL. GRUPO DE EXPERTOS/AS EN VIOLENCIA DOMÉSTICA Y DE GÉNERO DEL CGPJ. Guía de criterios de actuación judicial frente a la violencia de género, 2013, p. 113. Disponible en: www.poderjudicial.es. Acceso en: 30 de marzo de 2020. 
En la mencionada resolución se recogen una serie de factores a valorar por el tribunal en la credibilidad y verosimilitud de la declaración de la víctima de violencia de género. Expresamente se hace referencia a:

"1. Seguridad en la declaración ante el Tribunal por el interrogatorio del Ministerio Fiscal, letrado/a de la acusación particular y de la defensa.

2. Concreción en el relato de los hechos ocurridos objeto de la causa.

3. Claridad expositiva ante el Tribunal.

4. "Lenguaje gestual” de convicción. Este elemento es de gran importancia y se caracteriza por la forma en que la víctima se expresa desde el punto de vista de los "gestos" con los que se acompaña en su declaración ante el Tribunal.

5. Seriedad expositiva que aleja la creencia del Tribunal de un relato figurado, con fabulaciones, o poco creíble.

6. Expresividad descriptiva en el relato de los hechos ocurridos.

7. Ausencia de contradicciones y concordancia del iter relatado de los hechos.

8. Ausencia de lagunas en el relato de exposición que pueda llevar a dudas de su credibilidad.

9. La declaración no debe ser fragmentada.

10. Debe desprenderse un relato íntegro de los hechos y no fraccionado acerca de lo que le interese declarar y ocultar lo que le beneficie acerca de lo ocurrido.

11. Debe contar tanto lo que a ella y su posición beneficia como lo que le perjudica"72.

No se trata de analizar todos y cada uno de los ítems marcados. No obstante, entendemos que, en todos los factores referenciados entran en juego múltiples circunstancias como la propia personalidad de la víctima, su edad, sus habilidades sociales, e incluso su nivel intelectual, la mayor parte de ellos de apreciación más que subjetiva.

72 STS 119/2019, de 6 de marzo. ROJ: STS 678/2019 - ECLI:ES:TS:2019:678. 
Mucho tiene que decir, por tanto, en el campo del Derecho Procesal, la llamada Psicología del testimonio. Aunque la aproximación al estudio de esta ciencia excede el ámbito del presente trabajo, consideramos necesario hacer una breve referencia a las circunstancias objetivas que, en aplicación de la misma, han de ser tenidas en cuenta en la valoración de las declaraciones, a fin de ofrecer al juez los elementos necesarios para fundamentar su convicción, y que Nieva Fenoll ha sistematizado en: "coherencia de la declaración, contextualización del relato, existencia de corroboraciones del relato a través de otros elementos de prueba, y por último la presencia o ausencia de comentarios oportunistas en el declarante" 73 .

La primera de estas circunstancias objetivas, la coherencia en la declaración, es reconocida tanto por la doctrina jurisprudencial tradicional, como por la nueva línea introducida en la sentencia 119/2019 al referirse esta última a parámetros como "ausencia de contradicciones y concordancia del iter relatado de los hechos". Lo mismo podría decirse sobre la existencia de corroboraciones del relato a través de otros elementos de prueba.

Difícil encaje tienen en los parámetros recogidos por la resolución analizada las circunstancias de contextualización del relato y presencia o ausencia de comentarios oportunistas del declarante, si bien la primera podría encuadrarse en la "expresividad descriptiva en el relato de los hechos", y la segunda en el deber de "contar tanto lo que a ella y su posición beneficia como lo que le perjudica".

Por otro lado, uno de los parámetros señalados por el Tribunal Supremo como "de gran importancia”, el del lenguaje gestual de convicción es, precisamente, el que mayores dudas nos genera en orden a la objetivación del mismo.

La utilización de una especie de "pseudoconcepto" como el del "lenguaje gestual de convicción"74 acerca, a nuestro juicio, la valoración

73 NIEVA FENOLL, Jordi. Derecho Procesal III. Proceso Penal. Valencia: Tirant lo Blanch, 2019, p. 342.

74 En posterior resolución a la analizada, la STS 348/2019, de 4 de julio. precisa aún más el "lenguaje gestual" para referirse a "la forma en que la víctima transmite al Tribunal cómo ocurrieron los hechos, y de una manera donde los gestos en la mecánica de transmisión al Tribunal de lo que ella sintió cuando 
de la declaración de la víctima al campo de la Psicología Jurídica y de la credibilidad del testimonio, algo que como se desprende de todo lo anteriormente expuesto, no es necesariamente negativo, si no fuera porque la valoración de esa gestualidad está desacreditada actualmente por la doctrina ${ }^{75} \mathrm{y}$ excede con mucho la formación de nuestros juzgadores ${ }^{76}$, al acudir, como destaca Herrero Alonso, "a la necesidad de apreciación de factores que tienen que ver básicamente con indicadores de comunicación no verbal o a la consideración de cómo se declara", concluyendo que "es preciso que los operadores jurídicos sepan que no existe ningún indicador conductual, no verbal, que en y por sí mismo (o en una combinación prefijada con otros), del que podamos inferir con mínimas garantías que alguien está mintiendo o diciendo la verdad"77.

fue víctima permiten a éste adentrarse en la realidad de lo ocurrido de una forma eficaz”. ROJ: STS 2228/2019 - ECLI:ES:TS:2019:2228.

75 NIEVA FENOLL, Jordi. La discutible utilidad de los interrogatorios de partes y testigos. (Algunas reflexiones sobre la oralidad en tiempos de pandemia). Diario La Ley, n. 9672, 2020, p. 4.

76 DENAULT, Vincent, et al. The Analysis of Nonverbal Communication: The Dangers of Pseudoscience in Security and Justice Contexts. Anuario de Psicología Jurídica, n. 30, 2020, pp. 1-12. https://doi.org/10.5093/apj2019a9. Disponible en: https://journals.copmadrid.org/apj/art/apj2019a9. Acceso en: 30 de marzo de 2020. En el mismo sentido, Érice Martínez sostiene que "A ello debe añadirse que si bien en los interrogatorios de testigos e imputados ciertamente posee relevancia lo expuesto, la forma en que se manifiesta e incluso el lenguaje gestual, pero tales datos que no son unívocos, no poseen la aptitud en si mismos para basar una convicción racional de quien, no es especialista en su examen, y en muchas ocasiones no dispone de antecedentes clínicos o de otra índole que pudieran dotar de solidez a tales elementos, siendo lo más probable que aunque dispusiera de una adecuada habilitación técnica no pudiera obtener una información preciso en el marco formalizado y el breve tiempo de que se dispone en una única declaración en la vista oral. Por ello la valoración de estos medios probatorios debe desplazarse de aquellos aspectos más inaprensibles y menos controlables, a otro terreno más seguro, como lo es el contenido informativo de las declaraciones...", ÉRICE MARTÍNEZ, María Esther. La calidad de la prueba en violencia de género. En: ÉRICE MARTÍNEZ, María Esther (Dir.). Práctica y valoración de la prueba en violencia de género. Madrid: Cuadernos Digitales de Formación, Consejo General del Poder Judicial, 2009, p. 218.

77 HERRERO ALONSO, Carmen. Bases psico-jurídicas para confeccionar medidas y protocolos de actuación respecto al tratamiento de víctimas especialmente vulnerables. En: BUJOSA VADELL, Lorenzo-Mateo y DEL POZO PÉREZ, Marta (Dirs.). Protocolos de actuación con víctimas especialmente 
La técnica adecuada, como pone de manifiesto Nieva Fenoll, es analizar lo que el testigo dice y no lo que hace cuando declara ${ }^{78}$, teniendo en cuenta la propia falibilidad de la memoria humana ${ }^{79}$, la cual se va deteriorando por el mero trascurso del tiempo ${ }^{80}$.

No obstante lo señalado, el Alto Tribunal, en la referida resolución, es consciente del coste de una revictimización al reproducir la declaración ya realizada en sede policial y en fase de instrucción, y por ello señala otros factores que también pueden ser tenidos en cuenta en el proceso de valoración:

"1. Dificultades que puede expresar la víctima ante el Tribunal por estar en un escenario que le recuerda los hechos de que ha sido víctima y que puede llevarle a signos o expresiones de temor ante lo sucedido que trasluce en su declaración.

2. Temor evidente al acusado por la comisión del hecho dependiendo de la gravedad de lo ocurrido.

3. Temor a la familia del acusado ante posibles represalias, aunque estas no se hayan producido u objetivado, pero que quedan en el obvio y asumible temor de las víctimas.

4. Deseo de terminar cuanto antes la declaración.

5. Deseo al olvido de los hechos.

6. Posibles presiones de su entorno o externas sobre su declaración”81.

vulnerables: Una guía de buenas prácticas. Cizur Menor: Editorial Thomson Reuters Aranzadi, 2019, p. 31.

NIEVA FENOLL, Jordi. La discutible utilidad de los interrogatorios de partes y testigos. (Algunas reflexiones sobre la oralidad en tiempos de pandemia), Diario La Ley, n. 9672, 2020, p. 4.

79 El tema de las falsas memorias y su incidencia en el proceso penal ha sido desarrollado ampliamente por la doctrina brasileña. A título de ejemplo ver: ÁVILA, Gustavo N. Falsas Memórias e Sistema Penal: A prova testemunhal em xeque. Rio de Janeiro: Lumen Juris, 2013; BALDASSO, Flaviane; ÁVILA, Gustavo N. A. Repercussão do Fenômeno das Falsas Memórias na Prova Testemunhal: uma análise a partir dos Julgados do Tribunal de Justiça do Rio Grande do Sul. Revista Brasileira de Direito Processual Penal, Porto Alegre, vol. 4, n. 1, jan./abr. 2018, pp. 371-409.

80 AYALA YANCCE, Rafael. Credibilidad testimonial del testigo en el proceso penal. Revista Brasileira de Direito Processual Penal, Porto Alegre, vol. 6, n. 1, jan./abr. 2020, p. 457.

81 STS 119/2019, de 6 de marzo. ROJ: STS 678/2019 - ECLI:ES:TS:2019:678. 
Estos factores vendrían a matizar los once inicialmente señalados hasta el punto de que alguno de ellos podría ser considerado como "contra factor" de estos. Es evidente que, si la víctima tiene que mostrar "seguridad en la declaración ante el tribunal” ${ }^{2}$, difícilmente va a conseguir tal objetivo si está atemorizada por las posibles represalias del entorno del agresor. No obstante, y siendo conscientes de que el temor de las víctimas es una realidad, también hay que admitir que en muchas ocasiones la objetivación del mismo es altamente dificultosa si no es verbalizado por la propia víctima, con lo cual, a nuestro juicio, no debería tenerse en cuenta de manera generalizada para formar la convicción judicial, debiendo proceder el juez o tribunal sentenciador a una cuidadosa motivación de tales circunstancias. Y ello es aún más patente en los parámetros que hacen referencia a los deseos de las víctimas, algo que no puede presuponerse per se, por más lógico que pudiera parecer. Es cierto que la víctima puede ser coherente en su declaración, pero no lo es menos que esto no suele ser lo habitual ${ }^{83}$ en el ámbito de los delitos que nos ocupan.

Entendemos que cualquiera de las circunstancias mencionadas debe ser introducida en el plenario con todas las garantías para que puedan ser tenidas en cuenta por el juez o tribunal a la hora de formar su convicción.

Por último, debemos plantearnos si los criterios establecidos para la declaración de la víctima en la mencionada sentencia 119/2019, de 6 de marzo pueden considerarse como doctrina jurisprudencial consolidada en la materia o, por otro lado, no son más que una incipiente línea abierta por el Tribunal Supremo español en su intención de atribuir una posición privilegiada al testigo-víctima del delito.

Para responder a esta cuestión basta un breve análisis de la aplicación que de dichos criterios se ha hecho en diferentes resoluciones dictadas por el Alto Tribunal español con posterioridad a la sentencia

82 STS 119/2019, de 6 de marzo. ROJ: STS 678/2019 - ECLI:ES:TS:2019:678.

83 En este sentido Nieva Fenoll sostiene que "Los relatos de las víctimas, evidentemente, pueden ser coherentes y contextualizados, pero no suelen serlo, precisamente debido a la situación de estrés que han padecido, lo que hace que borren por completo algunos detalles que debieran ser obvios". NIEVA FENOLL, Jordi. Derecho Procesal III. Proceso Penal. Valencia: Tirant lo Blanch, 2019 , p. 351. 
analizada. Sin ánimo de exhaustividad, mencionaremos la Sentencia del Tribunal Supremo 458/2019, de 9 de octubre, donde se hace aplicación de los mencionados criterios para avalar la declaración de las víctimas en un proceso por delitos de atentado a la autoridad, lesiones y desórdenes públicos ${ }^{84}$. Y en el mismo sentido, se aplican en la Sentencia del Tribunal Supremo 495/2019, de 17 de octubre, en un proceso por delito continuado de abuso sexual y contra la salud pública ${ }^{85}$.

De manera que criterios que inicialmente fueron de aplicación al ámbito de la violencia de género, han extendido su radio de acción a otras figuras delictivas, generalizando su aplicación, por tanto, al testimonio de cualquier víctima cualesquiera que sean los delitos objeto de enjuiciamiento.

Esta conclusión inicial que pudiera parecer lógica, sin embargo, aparece desvirtuada por el análisis de las muchas sentencias del Tribunal Supremo que no aluden a los criterios sentados por la sentencia 119/2019 y optan por aplicar los presupuestos tradicionalmente consolidados de ausencia de incredibilidad subjetiva, verosimilitud del testimonio y persistencia en la incriminación ${ }^{86}$.

\section{CONCLUSIONES}

La doctrina jurisprudencial consolidada por el Tribunal Supremo español en relación al valor probatorio de la declaración de la víctima cuando la misma constituye la única prueba de cargo para enervar la presunción constitucional de inocencia, ha sufrido recientemente la ampliación de los parámetros orientativos a tener en cuenta en dicha valoración. Sólo el tiempo podrá decir si esta nueva línea, que se inicia en

84 STS 458/2019, de 9 de octubre. ROJ: STS 3124/2019 - ECLI:ES:TS:2019:3124 STS 495/2019, de 17 de octubre. ROJ: STS 3204/2019 - ECLI:ES:TS:2019:3204. Entre otras, la STS $410 / 2019$, de 20 de septiembre, ROJ: STS 2902/2019 - ECLI:ES:TS:2019:2902, seguida por un delito de abusos sexuales; la STS 468/2019, de 14 de octubre, ROJ: STS 3312/2019 - ECLI:ES:TS:2019:3312, en un asunto de abuso sexual; la STS 527/2019, de 31 de octubre, ROJ: STS 3501/2019 - ECLI:ES:TS:2019:3501, seguida por un delito continuado de agresión sexual; o la STS 544/2019, de 13 de noviembre, ROJ: STS 3702/2019 ECLI:ES:TS:2019:3702, seguida por un delito de trata de seres humanos. 
un asunto relacionado con la violencia de género, puede considerarse o no consolidada. Mientras tanto, podemos hacer una serie de valoraciones preliminares, que nos permitan hacer algunos planteamientos con perspectiva de futuro.

A lo largo de este trabajo, se ha evidenciado que, con la intención de apuntalar los criterios jurisprudenciales tradicionales sobre los que pivota la declaración de la víctima y que han sido analizados anteriormente, el Tribunal Supremo español da una vuelta de tuerca a la mencionada doctrina, consiguiendo, a nuestro juicio, el efecto contrario del pretendido ${ }^{87}$ por diversas razones que pasamos a exponer.

En primer lugar, porque entendemos que no era necesaria tal exhaustividad en el desarrollo de los parámetros tradicionalmente establecidos, lo que ha provocado una sobrevaloración del principio de inmediación, que alcanza así un poder casi omnímodo. Quizás es el momento de recordar las palabras plasmadas por el Alto Tribunal cuando decía que "el mito de la inmediación debe ceder ante la tutela judicial efectiva que sólo es posible mediante la racional, metódica y analítica disección de las pruebas interrelacionadas de forma lógica"88.

En segundo lugar, como reiteradamente hemos puesto de manifiesto, los parámetros o criterios consolidados en la doctrina jurisprudencial de nuestro Tribunal Supremo, son precisamente orientativos, lo cual encaja perfectamente con el principio de libre valoración de la prueba que rige en el sistema procesal penal español. Pretender que la declaración de la víctima tenga un valor diferenciado como medio de prueba ${ }^{89}$, mediante el establecimiento de unos criterios

87 Por el contrario, mostrando su absoluta conformidad con los criterios introducidos por el Tribunal Supremo: GALDEANO SANTAMARÍA, Ana María. Estatuto de la víctima y violencia de género. Convenio de Estambul. Nuestro futuro más próximo. Madrid: Centro de Estudios jurídicos (CEJ), p. 35. Disponible en: http://www.cej-mjusticia.es/cej_dode/flash/ebook/assets/ img/cejponencia1563350666745/cejponencia1563350666745.pdf. Acceso en: 30 de marzo de 2020.

STS 1063/2006, de 26 de septiembre. ROJ: STS 6995/2006 - ECLI: ES:TS:2006:6995.

89 Según la STS 282/2018, de 13 de junio, "En este debate, tuvo la oportunidad de resolver este problema la Ley 4/2015, de 27 de abril, del Estatuto de la víctima del delito, al poder llevar a cabo una modificación de la LECRIM que habilitara 
de valoración de la credibilidad, es sencillamente introducir los sesgos propios del sistema de prueba legal o tasada en nuestro ordenamiento jurídico, por más que se pretenda afirmar lo contrario ${ }^{90}$. Si además, como parece deducirse de algunas de las resoluciones analizadas, estos son de aplicación a la declaración de la víctima de cualquier delito, estaremos introduciendo de facto por vía jurisprudencial en el ordenamiento procesal español, y en concreto en lo que se refiere a la prueba testifical, un estatuto procesal diferenciado y privilegiado para la víctima del delito cuando en ella confluye también la condición de testigo, algo que, a nuestro entender, corresponde exclusivamente al legislador.

Por otro lado, como único efecto positivo de esta nueva tendencia jurisprudencial, consideramos el de añadir un plus al deber de motivación de las resoluciones judiciales, en la medida en que, si partimos, como no podía ser de otro modo, de la inmediación con que se practica la declaración como una herramienta para la valoración de la misma, la racionalidad de la decisión basada en los mencionados parámetros debe plasmarse en una cuidada y adecuada motivación.

Por último, y por lo que respecta específicamente a la víctima de un delito de violencia de género, a nuestro juicio, estos criterios colocan a la misma en una posición aún más difícil de la que ya de por sí tiene en el proceso penal. Pensamos en aquella mujer que ha sufrido malos tratos a manos de su pareja o ex pareja, y a la que ahora no le bastará con relatar lo ocurrido ante la autoridad judicial, sino que además, por mor de la mencionada sentencia, deberá hacerlo de una determinada manera para resultar creíble.

En definitiva, consideramos que el Tribunal Supremo español ha caído en el propio estereotipo que pretende evitar. Entendemos que los factores señalados no responden más que a lo que se espera de una mujer víctima de violencia de género, conformando así un estereotipo en sí mismo ${ }^{91}$, obviando las peculiares características que concurren en este

una especial y privilegiada posición de la víctima del delito desde el punto de vista del proceso penal”. ROJ: STS 2182/2018 - ECLI:ES:TS:2018:2182.

90 MAGRO SERVET, Vicente. Análisis de la Doctrina Jurisprudencial reciente en violencia de género. Diario La Ley, n. 9278, 2018, p. 10.

91 En relación a la valoración de la declaración de la víctima sin estereotipos, ver: MARÍN LÓPEZ, María Paloma. La declaración de la víctima de la violencia 
tipo de delitos, y que llevan a que las respuestas que dan las víctimas de los mismos no sean las que pudieran esperarse en la víctima de cualquier otro delito ${ }^{92}$. Lo normal es que la víctima de violencia de género se sienta insegura y nerviosa al narrar los hechos; no sólo por la presencia, en la mayoría de los casos, del maltratador en la misma sala, sino por otros factores de sentido común, como la incertidumbre de ser creída, el hecho de llevar hasta la justicia al padre de sus hijos, o al hombre que ha amado y con el que ha compartido su vida, el tener que contar ante unos extraños detalles íntimos de su relación, etc.

Los operadores jurídicos que trabajan y han trabajado en el campo de la violencia de género saben lo complicado que es conseguir que la víctima reviva lo sucedido en el acto del juicio, que se mantenga firme en su decisión de declarar, como para ahora tener que "instruirla" sobre una forma de contarlo o sobre los gestos que debe o no debe hacer para resultar creíble.

Es el momento de recordar, como pone de manifiesto acertadamente San Miguel Bergareche que "lo que ha de acreditarse, más allá de toda duda razonable, no es la cualidad de creíble o de verosímil, sino la certeza"93, con hechos objetivos y contrastados que permitan la adecuada contradicción y el adecuado ejercicio del derecho de defensa.

Sin duda, los parámetros introducidos por la sentencia del Tribunal Supremo 119/2019, de 6 de marzo, facilitan la labor del juzgador en la valoración de la declaración de las víctimas, pero también es cierto que colocan a estas en una incómoda posición al percibir que su declaración ha de alcanzar determinados estándares para resultar

de género: apuntes para una valoración libre de estereotipos de género. En: MARÍN LÓPEZ, María Paloma (Dir.). Impartición de justicia con perspectiva de género en los distintos órdenes jurisdiccionales. Madrid: Cuadernos Digitales de Formación, Consejo General del Poder Judicial), 2016, pp. 99-105.

92 Ejemplo de ello es la falta de colaboración de las víctimas de violencia de género en la persecución del delito, mediante un importante número de retiradas de denuncia o mediante el acogimiento a la dispensa del deber de declarar.

93 SAN MIGUEL BERGARECHE, Miren Nekane. Perspectiva de género en Derecho Penal. En: ¿Qué significa “enjuiciamiento con perspectiva de género? Madrid: Cuadernos Digitales de Formación, Consejo General del Poder Judicial), 2019, p. 7. 
creíble, un temor, por otro lado, muy generalizado en la práctica entre las víctimas de violencia de género.

Tenemos que tener en cuenta que, si elevamos la presión sobre la víctima de violencia de género o, más concretamente, si la víctima percibe una mayor dificultad en la posición que ocupa en el proceso penal, habremos emprendido el camino contrario a su necesario empoderamiento, el cual se evidencia como imprescindible para conseguir que se mantenga en el proceso y que el mismo concluya con una sentencia condenatoria.

\section{BIBLIOGRAFÍA}

ARCE FERNÁNDEZ, Ramón; FARIÑA RIVERA, Francisca. La posible simulación de la víctima. Evaluación psicológico-forense de la credibilidad y el daño psíquico mediante el sistema de evaluación global. En: RIVAS VALLEJO, María Pilar; BARRIOS BAUDOR, Guillermo Leandro (Dirs.). Violencia de Género. Perspectiva Multidisciplinar y Práctica Forense. Cizur Menor: Thomson Reuters Aranzadi, 2014, pp. 357-367.

ASOCIACIÓN DE MUJERES JURISTAS THEMIS. Evaluación del tratamiento judicial de la violencia de género en el ámbito de la pareja. Disponible en: https:// www.mujeresjuristasthemis.org/funcion-themis/biblioteca/category/15-penal. Acceso en: 25 de marzo de 2020.

ÁVILA, Gustavo N. Falsas Memórias e Sistema Penal: A prova testemunhal em xeque. Rio de Janeiro: Lumen Juris, 2013.

AYALA YANCCE, Rafael. Credibilidad testimonial del testigo en el proceso penal. Revista Brasileira de Direito Processual Penal, Porto Alegre, vol. 6, n. 1, jan./abr. 2020, pp. 453-480. https://doi.org/10.22197/rbdpp.v6i1.246

BALDASSO, Flaviane; ÁVILA, Gustavo N. A. Repercussão do Fenômeno das Falsas Memórias na Prova Testemunhal: uma análise a partir dos Julgados do Tribunal de Justiça do Rio Grande do Sul. Revista Brasileira de Direito Processual Penal, Porto Alegre, vol. 4, n. 1, jan./abr. 2018, pp. 371-409. https://doi.org/10.22197/ rbdpp.v4i1.129

BALERDI MÚGICA, José Manuel. El testimonio en delitos de violencia de género en la jurisprudencia. Valoración y efectos probatorios”. En: ÉRICE MARTÍNEZ, María Esther (Dir.). Práctica y valoración de la prueba en violencia de género. Madrid: Cuadernos Digitales de Formación, Consejo General del Poder Judicial, 2009, pp. 52-115. 
CABEZUDO RODRÍGUEZ, Nicolás. Del principio de inmediación, sus excepciones y los instrumentos tecnológicos. Valencia: Tirant lo Blanch, 2010.

CASTILLEJO MANZANARES, Raquel; SERRANO MASSIP, Mercedes. Denuncia y dispensa del deber de declarar. En: CASTILLEJO MANZANARES, Raquel (Dir.). Violencia de género y justicia. Santiago de Compostela: Universidade de Santiago de Compostela, 2013, pp. 549-580.

CONSEJO GENERAL DEL PODER JUDICIAL, GRUPO DE EXPERTOS Y EXPERTAS EN VIOLENCIA DOMÉSTICA Y DE GÉNERO DEL CGPJ. Estudio sobre la Aplicación de la Ley Integral contra la violencia de género por las Audiencias Provinciales. Disponible en: www.poderjudicial.es. Acceso en: 22 de marzo de 2020.

CONSEJO GENERAL DEL PODER JUDICIAL. Datos estadísticos proporcionados por el Observatorio contra la Violencia Doméstica y de Género del Consejo General del Poder Judicial (2007-2018). Disponible en: www.poderjudicial.es. Acceso en: 22 de marzo de 2020.

CONSEJO GENERAL DEL PODER JUDICIAL. GRUPO DE EXPERTOS/AS EN VIOLENCIA DOMÉSTICA Y DE GÉNERO DEL CGPJ. Guía de criterios de actuación judicial frente a la violencia de género. Disponible en: www.poderjudicial.es. Acceso en: 25 de marzo de 2020.

DENAULT, Vincent, et al. The Analysis of Nonverbal Communication: The Dangers of Pseudoscience in Security and Justice Contexts. Anuario de Psicología Jurídica, n. 30, 2020, pp. 1-12. https://doi.org/10.5093/apj2019a9

ÉRICE MARTÍNEZ, María Esther. La calidad de la prueba en violencia de género. En: ÉRICE MARTÍNEZ, María Esther (Dir.). Práctica y valoración de la prueba en violencia de género. Madrid: Cuadernos Digitales de Formación, Consejo General del Poder Judicial, 2009, pp. 208-223.

FISCALÍA GENERAL DEL ESTADO. Memorias Anuales (2006-2018).

FUENTES SORIANO, Olga. El enjuiciamiento de la violencia de género. Madrid: Editorial Iustel, 2009.

FUENTES SORIANO, Olga. Investigación y prueba de los delitos de violencia contra la mujer. En: GONZÁLEZ-CUELLAR SERRANO, Nicolás (Dir.). Investigación y prueba en el proceso penal. Madrid: Colex, 2006, pp. 245-264.

FUENTES SORIANO, Olga. Los procesos por violencia de género. Problemas probatorios tradicionales y derivados del uso de las nuevas tecnologías. Revista General de Derecho Procesal, n. 44, 2018, pp. 1-39.

GALDEANO SANTAMARÍA, Ana María. Estatuto de la víctima y violencia de género. Convenio de Estambul. Nuestro futuro más próximo. Madrid: Centro de Estudios jurídicos (CEJ). Disponible en: http://www.cej-mjusticia.es/cej_dode/flash/ 
ebook/assets/img/cejponencia1563350666745/cejponencia1563350666745. pdf. Acceso en: 30 de marzo de 2020.

HERRERO ALONSO, Carmen. Bases psico-jurídicas para confeccionar medidas y protocolos de actuación respecto al tratamiento de víctimas especialmente vulnerables. En: BUJOSA VADELL, Lorenzo-Mateo y DEL POZO PÉREZ, Marta (Dirs.). Protocolos de actuación con víctimas especialmente vulnerables: Una guía de buenas prácticas. Cizur Menor: Editorial Thomson Reuters Aranzadi, 2019, pp. 23-40.

LUACES GUTIÉRREZ, Ana Isabel. La exención del deber de declarar de las víctimas de violencia de género. Práctica de Tribunales, n. 101, 2013, pp. 46-57.

MAGRO SERVET, Vicente. Análisis de la Doctrina Jurisprudencial reciente en violencia de género. Diario La Ley, n. 9278, 2018, pp. 1-13.

MAGRO SERVET, Vicente. Hacia una ley integral de la víctima en el proceso penal: una propuesta sistemática. Diario La Ley, n. 7226, 2009, pp. 1-16.

MAGRO SERVET, Vicente. La imposibilidad de conceder a las víctimas de la violencia de género la dispensa de declarar contra sus agresores (art. 416 LECrim): ¿es necesaria una reforma legal?. Diario La Ley, n. 6333, 2005, pp. 1-20.

MAGRO SERVET, Vicente. La valoración de la declaración de la víctima en el proceso penal (especial referencia a la viabilidad de la prueba pericial acerca de la veracidad de su testimonio). Diario La Ley, n. 7013, 2008, pp. 1-15.

MARÍN LÓPEZ, María Paloma. La declaración de la víctima de la violencia de género: apuntes para una valoración libre de estereotipos de género. En: MARÍN LÓPEZ, María Paloma (Dir.). Impartición de justicia con perspectiva de género en los distintos órdenes jurisdiccionales. Madrid: Cuadernos Digitales de Formación, Consejo General del Poder Judicial), 2016, pp. 94-109.

MARTÍN DIZ, Fernando. Presunción de inocencia en procesos penales por violencia de género. Revista Ius et Praxis, n. 3, 2018, pp. 19-66. http://dx.doi.org/10.4067/ S0718-00122018000300019

MARTÍN RÍOS, María Pilar. Reflexiones acerca de la negativa a declarar en juicio de la mujer víctima de violencia de género: análisis de la jurisprudencia española. Revista General de Derecho Procesal, n. 15, 2008, pp. 1-11.

MARTÍN RÍOS, María Pilar. Víctima y justicia penal: reparación, intervención y protección de la víctima en el proceso penal. Barcelona: Editorial Atelier, 2012.

MIRANDA ESTAMPRES, Manuel. Particularidades de la prueba en los delitos de violencia de género. En: DE HOYOS SANCHO, Montserrat (Dir.). Tutela jurisdiccional frente a la violencia de género. Aspectos procesales, civiles, penales y laborales. Valladolid: Editorial Lex Nova, 2009, pp. 453-454. 
MONTESINOS GARCÍA Ana. Especificidades probatorias en los procesos por violencia de género. Revista de Derecho Penal y Criminología, n. 17, 2017, pp. 127-165.

MORENO CATENA, Víctor y CORTÉS DOMÍNGUEZ, Valentín. Derecho Procesal Penal. Valencia: Tirant lo Blanch, 2019.

NIEVA FENOLL, Jordi. Derecho Procesal III. Proceso Penal. Valencia: Tirant lo Blanch, 2019.

NIEVA FENOLL, Jordi. La discutible utilidad de los interrogatorios de partes y testigos. (Algunas reflexiones sobre la oralidad en tiempos de pandemia). Diario La Ley, n. 9672, 2020, pp. 1-12.

ORTIZ PRADILLO, Juan Carlos. Estereotipos legales en la lucha contra la violencia machista: la irrelevancia jurídica de la voluntad de la víctima (1). Diario La Ley, n. 8697,2016 , pp. 1-24.

PIÑEIRO ZABALA, Igor. Testigo y víctima: Dispensa a declarar. Diario La Ley, n. 7519, 2010, pp. 1-15.

RAMÍREZ ORTIZ, José Luis. Perspectiva de género, prueba y proceso penal: Una reflexión crítica. Valencia: Tirant lo Blanch, 2019.

SAN MIGUEL BERGARECHE, Miren Nekane. Perspectiva de género en Derecho Penal. En: ¿Qué significa “enjuiciamiento con perspectiva de género?. Madrid: Cuadernos Digitales de Formación, Consejo General del Poder Judicial), 2019, pp. 1-10.

SERRANO MASSIP, Mercedes. La víctima de la violencia de género ante el deber de denunciar y declarar en el proceso penal. Revista General de Derecho Procesal, n. 29, 2013, pp. 1-50.

TARDÓN OLMOS, María. Dificultades probatorias en los procedimientos por delitos de violencia de género. En: CUETO MORENO, Cristina; GÓMEZ VILLORIA, José María (Dirs.). Criterios de actuación judicial frente a la violencia de género. Madrid: Cuadernos Digitales de Formación, Consejo General del Poder Judicial, 2014, pp. 98-133.

VELASCO NÚÑEZ, Eloy. “Conclusiones del Seminario La prueba en el proceso penal”. Madrid: Conclusiones de Seminarios, Consejo General del Poder Judicial, 2008, pp. 1-22. 


\section{Informações adicionais e declarações dos autores (integridade científica}

Declaração de conflito de interesses (conflict of interest declaration): a autora confirma que não há conflitos de interesse na realização das pesquisas expostas e na redação deste artigo.

Declaração de autoria e especificação das contribuições (declaration of authorship): todas e somente as pessoas que atendem os requisitos de autoria deste artigo estão listadas como autores; todos os coautores se responsabilizam integralmente por este trabalho em sua totalidade.

Declaração de ineditismo e originalidade (declaration of originality): a autora assegura que o texto aqui publicado não foi divulgado anteriormente em outro meio e que futura republicação somente se realizará com a indicação expressa da referência desta publicação original; também atesta que não há plágio de terceiros ou autoplágio.

\section{Dados do processo editorial}

(http://www.ibraspp.com.br/revista/index.php/RBDPP/about/editorialPolicies)

- Recebido em: 27/04/2020

- Controle preliminar e verificação de plágio: 28/04/2020

- Avaliação 1: 12/05/2020

- Avaliação 2: 28/05/2020

- Avaliação 3: 19/05/2020

- Decisão editorial preliminar: 28/06/2020

- Retorno rodada de correções: 14/07/2020

- Decisão editorial final: 16/07/2020
Equipe editorial envolvida

- Editor-chefe: 1 (VGV)

- Editor-assistente: 1 (GNA)

- Revisores: 3 


\section{COMO CITAR ESTE ARTIGO:}

GONZÁLEZ MONJE, Alicia. La declaración de la víctima de violencia de género como única prueba de cargo: últimas tendencias jurisprudenciales en España. Revista Brasileira de Direito Processual Penal, Porto Alegre, vol. 6, n. 3, p. 1627-1660, set./dez. 2020. https://doi.org/10.22197/rbdpp.v6i3.377

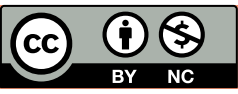

Esta obra está licenciada com uma Licença Creative Commons Atribuição-NãoComercial 4.0 Internacional. 